\title{
Complicações Pós-Aborto Provocado: Fatores Associados
}

\section{Factors Associated with Complications Following Induced Abortion}

\author{
Ellen Hardy ${ }^{1}$ \\ Graciana Alves ${ }^{2}$
}

HARDY, E. \& ALVES, G. Factors Associated with Complications Following Induced Abortion. Cad. Saúde Públ., Rio de Janeiro, 8 (4): 454-458, oct/dec, 1992.

Illegal induced abortion exposes women to risks and complications. These decrease when the abortion is carried out safely. Complications resulting from unsafe abortions can cause death or may affect future pregnancies, increasing ectopic pregnancy and spontaneous abortion, for example. The purpose of this paper is to present Brazilian data on the association between complications caused by illegal induced abortions and the conditions in which they are performed. The study was done in 1990 in a Brazilian university. Data was obtained through a questionnaire distributed to all the female employees and graduate students. Forty-two percent of the students and 27\% of the employees responded; 82 students and 264 employees had had at least one illegal abortion; 15 and 50, respectively, had suffered health problems (complications) after the last one. The women whose abortions had been done by physicians, in a clinic or hospital, and using modern techniques presented fewer complications. Younger women were not significantly different from the others when frequency of complications was studied. However, this group was composed mainly of students with a higher level of education and more economic resources.

Keywords: Induced Abortion; Complications; Unsafe Abortion

\section{INTRODUÇÃO}

O aborto provocado expõe a mulher a riscos e complicaçōes severas. Tais riscos variam consideravelmente, de acordo com as circunstâncias nas quais é feito o aborto. Ao mesmo tempo, as pesquisas médicas mostram que, quando realizado em boas condições, o risco de complicações do aborto torna-se muito pequeno (Tietze \& Henshaw, 1986). Do contrário, se realizado na clandestinidade, chega a representar um grande perigo (Barroso \& Cunha, 1980).

As complicações do aborto clandestino incluem perfuração do útero, retenção de restos de placenta, seguida de infeç̧ão, peritonite,

\footnotetext{
${ }^{1}$ Departamento de Tocoginecologia da Faculdade de Ciências Médicas da Universidade Estadual de Campinas Caixa Postal 6181, 13081-170, Campinas, SP, Brasil.

${ }^{2}$ Centro de Pesquisas e Controle das Doenças Materno-Infantis de Campinas. Cidade Universitária "Zeferino Vaz". Caixa Postal 6181, 13081-170.

Campinas, $S P$, Brasil.
}

tétano, e septicemia. As seqüelas ginecológicas incluem a esterilidade e também inflamaçōes das trompas e sinéquias uterinas. $\mathrm{O}$ risco e a gravidade das complicações crescem com o avanço da gestação (Barroso \& Cunha, 1980; Tietze \& Henshaw, 1986).

Tietze \& Henshaw (1986) afirmaram que a incidência das complicações do aborto está relacionada com a forma como ele é realizado. Entretanto, existe pouca informação concreta que mostre esta relação, exceto a experiência internacional que aponta a redução das complicações quando o aborto é legalizado, ou o aumento das mesmas, quando torna-se ilegal.

As complicações resultantes de abortos malfeitos podem levar à morte (Verardo, 1987), tanto quanto podem afetar as subsequientes gestaçōes, aumentando o risco de prematuridade, gravidez ectópica, abortamento espontâneo, e baixo peso ao nascer (Schor, 1991). O controle de tais complicações constitui um problema sério, principalmente para as mulheres residen- 
tes em comunidades pobres, com poucos serviços médicos disponíveis (Ladipo, 1987).

No Brasil, apesar do muito que se fala do assunto, não se encontram evidências, na literatura nacional, que confirmem a relação entre complicaçōes do aborto ilegal e as condições de sua prática. Os estudos brasileiros que fazem referência às complicações apresentam informações obtidas de mulheres hospitalizadas por abortamento provocado. Consequientemente, descrevem as características de mulheres com complicações que não podem ser comparadas com aquelas que não foram hospitalizadas. Isto nos motivou a analisar, em um grupo de mulheres que declararam ter feito aborto, as variáveis associadas às complicações, dentro de uma pesquisa mais ampla sobre a experiência com aborto entre alunas e funcionárias de uma universidade.

\section{MATERIAL E MÉTODO}

Este trabalho é uma análise secundária dos dados obtidos através de uma pesquisa desenvolvida em 1990 numa universidade brasileira. A população alvo dessa pesquisa esteve constituída de todas as funcionárias $\mathrm{e}$ alunas da graduação. As informações foram colhidas através de um questionário pré-testado com funcionárias e alunas de uma das faculdades. Detalhes da metodologia deste estudo já foram publicados previamente (Hardy et al., 1991).

À medida que os questionários respondidos foram sendo devolvidos, estes eram revisados, checando-se a sua consistência. As respostas foram digitadas duas vezes, por pessoas diferentes, utilizando-se o módulo de entrada de dados do SPSS PC-DE. Procedeu-se também à correção das inconsistências e dos erros lógicos.

Foram recebidos 937 questionários respondidos por alunas e 1987 respondidos por funcionárias, o que correspondeu a $42 \%$ e $27 \%$ de respostas, respectivamente. Oitenta e duas alunas e 264 funcionárias tinham feito pelo menos um aborto. Este trabalho analisa algumas características do último aborto provocado feito por cada uma destas 346 mulheres, das quais 65 $(18,8 \%)$ declararam sofrer complicações pós-aborto. Praticamente a metade destas últimas ficou internada pelo menos um dia, enquanto
$27 \%$ ficaram internadas durante três dias ou mais. Quase todas (88\%) tomaram algum remédio, a metade teve que fazer curetagem, $\mathrm{e}$ $14 \%$ acabaram fazendo uma cirurgia. Foi estudada a associação entre ocorrência de complicaçōes e idade da mulher, bem como as circunstâncias e características da realização do aborto. Os dados foram analisados utilizando-se o Statistical Package for Social Science - PC (SPSS-PC) e o Statistical Analysis System (SAS). Para estudar a significação estatística das diferenças observadas, foi utilizado o teste de qui-quadrado para tabelas de contingência. Para controlar pela relação que as variáveis independentes têm entre si, utilizou-se a técnica de regressão logística de Cox (1970). Nas tabelas são apresentados somente os valores de $\mathrm{p}<0,05$.

\section{RESULTADOS}

As mulheres abaixo de $\mathbf{2 0}$ anos, por ocasião do aborto, tiveram a mais alta porcentagem de complicações, chegando a ser o dobro daquelas com 30 ou mais anos (Tabela 1). A porcentagem de complicações aumentou significativamente com o tempo de gestação por ocasião do aborto, sendo mais de duas vezes superior quando realizado aos três meses ou mais, em comparação com o primeiro mês (Tabela 2).

TABELA 1. Complicaçōes do Aborto Induzido, Segundo a Idade, em Anos Completos, Quando Aconteceu. Em Porcentagem (\%)

\begin{tabular}{lccc}
\hline \hline \multirow{2}{*}{ Complicações } & \multicolumn{3}{c}{ Anos Completos } \\
\cline { 2 - 4 } & Até 19 & $20-29$ & $\begin{array}{c}30 \text { ou } \\
\text { mais }\end{array}$ \\
\hline Sim & 28 & 18 & 14 \\
Não & 72 & 82 & 86 \\
\hline Total de Mulheres* & 50 & 210 & 78 \\
\hline \hline
\end{tabular}

- Faltou informaçåo de cinco mulheres.

Com relação ao local onde foi feito o aborto, houve significativamente menos complicações entre as mulheres que o fizeram num hospital, clínica ou consultório, comparadas com as que 
abortaram na própria casa ou na casa de outra pessoa (Tabela 3).

TABELA 2. Complicações do Aborto Induzido, Segundo o Tempo de Gestação Quando foi Feito. Em Porcentagem (\%)

\begin{tabular}{lrcc}
\hline & \multicolumn{3}{c}{ Meses de Gestação } \\
\cline { 2 - 4 } Complicações $^{1}$ & 1 & 2 & 3 ou + \\
\hline Sim & 13 & 20 & 30 \\
Não & 87 & 80 & 70 \\
\hline Total de Mulheres $^{2}$ & 151 & 138 & 50 \\
\hline
\end{tabular}

${ }^{1}$ Quatro mulheres não sabiam o mês da gestação.

21 versus 3 ou mais meses, $p<0,01$.

TABELA 3. Complicações do Aborto Induzido, Segundo o Local Onde foi Feito. Em Porcentagem (\%)

\begin{tabular}{lccc}
\hline & \multicolumn{3}{c}{ Local } \\
\cline { 2 - 4 } Complicaçỏes & $\begin{array}{c}\text { Casa de } \\
\text { Outro }\end{array}$ & $\begin{array}{c}\text { Casa da } \\
\text { Mulher }\end{array}$ & $\begin{array}{c}\text { Clínica/ } \\
\text { Hospital }\end{array}$ \\
\hline Sim & 54 & 48 & 12 \\
Não & 46 & 52 & 88 \\
\hline Total de Mulheres* & 39 & 23 & 278 \\
\hline \hline
\end{tabular}

"Três mulheres não responderam, $p<0,0001$.

Foi significativamente maior a porcentagem de mulheres que tiveram complicaçōes entre as que fizeram o aborto com sonda ou agulha, comparadas às que utilizaram outros métodos: curetagem, aspiração ou remédios (Tabela 4).

TABELA 4. Complicações do Aborto Induzido, Segundo o Método Utilizado. Em Porcentagem (\%)

\begin{tabular}{lcc}
\hline \hline \multirow{2}{*}{ Complicações } & \multicolumn{2}{c}{ Métodos } \\
\cline { 2 - 3 } & $\begin{array}{c}\text { Sonda/ } \\
\text { Agulha }\end{array}$ \\
\hline Sim & 51 & 17 \\
Não & 49 & 83 \\
\hline Total de Mulheres * & 39 & 270 \\
\hline \hline
\end{tabular}

" Faltou informação de 32 mulheres, $p<0,0001$.
Também foi estudada a freqüência de complicações segundo a qualificação da pessoa que fez o aborto. As complicações foram cinco vezes menos frequientes quando o aborto foi feito por médico, em comparação com os nãoprofissionais, e três vezes menos frequiente quando feito por enfermeiras ou parteiras (Tabela 5).

TABELA 5. Complicaçðes do Aborto Induzido, Segundo a Pessoa que o Fez. Em Porcentagem (\%)

\begin{tabular}{lccc}
\hline \hline & & & \multicolumn{2}{c}{ Pessaa } \\
\cline { 2 - 4 } Complicaçōes & Médico & $\begin{array}{c}\text { Enfermeira/ } \\
\text { Parteira }\end{array}$ & $\begin{array}{c}\text { Nảo } \\
\text { Profissional }\end{array}$ \\
\hline Sim & 11 & 33 & 55 \\
Não & 89 & 67 & 45 \\
\hline Total de Mulheres $^{*}$ & 266 & 21 & 42 \\
\hline \hline
\end{tabular}

* Faltou informação de 14 mulheres, $\mathrm{p}<0,0001$.

A análise por regressão logística revelou que, quando cada variável independente foi controlada por todas as outras, apenas a realização do aborto fora do hospital ou clínica revelou-se estatisticamente associada à complicação do aborto (Tabela 6).

TABELA 6. Fatores Significativamente Associados a Complicaçöes Produzidas por Aborto Provocado pela Análise de Regressāo Logistica

\begin{tabular}{lccc}
\hline \hline Variável & $\mathrm{X} 2$ & $\mathrm{p}$ & $\mathrm{r}$ \\
\hline Aborto feito em casa & 35,30 & $<0,0001$ & 0,342 \\
\hline \hline
\end{tabular}

\section{DISCUSSÃO}

Os resultados confirmaram o esperado. As mulheres que tiveram o aborto realizado mais precocemente, por médico, em clínica ou hospital, e praticado por métodos mais modernos apresentaram menos complicaçōes. Ao estudar a associação entre idade e problemas de saúde pós-aborto, as mulheres mais jovens não foram diferentes das outras com relação à freqüência das complicações. Entretanto, este grupo esteve representado principalmente por alunas que, naturalmente, possuem maior nível de educação 
e geralmente mais recursos econômicos. A perda da associação entre complicações de aborto com idade gestacional, com quem o fez e o modo como foi feito, ao se fazer a regressão logística, deve ser o resultado da estreita associação entre estas variáveis independentes e o local em que o aborto foi praticado. Como esta última variável era a que apresentava maior correlação com complicações, foi a que permaneceu ao fim da regressão logística.

A população de mulheres que provocou aborto, estudada no presente trabalho, não é representativa das mulheres que recorrem ao aborto provocado na cidade onde foi realizada a pesquisa, nem das mulheres brasileiras. Um desvio evidente foi a menor representação de mulheres com menos escolaridade e de baixo nível sócio-econômico dentro do grupo que respondeu ao questionário.

Entretanto, é materialmente impossivel ter uma amostra que seja realmente representativa das mulheres que provocam aborto. Por outro lado, como a análise limita-se às condições e circunstâncias em que foi realizado o aborto, é difícil imaginar de que forma a falta de representatividade poderia afetar os resultados obtidos.

É corriqueiro que se fale que quanto piores as condições em que se realiza o aborto e a técnica utilizada, bem como quanto menor a qualificação de quem o faz, maiores as possibilidades de complicações e piores as conseqüências para a mulher que o sofre. É evidente que quanto menores os recursos econômicos das mulheres, piores as condições em que será feito o aborto. Conclui-se, portanto, que o aborto provocado é de risco apenas para quem não tem condições econômicas para pagar a sua realização com as melhores condições técnicas e por pessoal especializado.

O presente estudo proporciona dados que confirmam esta hipótese, já que inclui tanto mulheres que tiveram complicações como um grupo sem complicações. Isto o diferencia da maior parte dos trabalhos já desenvolvidos, que se referem a estatísticas hospitalares e incluem apenas mulheres que apresentaram complicações.

\section{RESUMO}

\section{HARDY, E. \& ALVES, G. Complicaçōes}

Pós-Aborto Provocado: Fatores Associados. Cad. Saúde Públ, Rio de Janeiro, 8 (4): 454458, out/dez, 1992.

O aborto provocado expõe a mulher a riscos e complicaçōes. Estes diminuem quando o aborto é feito em boas condiçöes. As complicações resultantes de abortos mal feitos podem levar à morte ou afetar as gestaçōes futuras, aumentando, por exemplo, a gravidez ectópica e o abortamento espontâneo. $\mathrm{O}$ objetivo do presente trabalho é apresentar dados brasileiros sobre a relação entre complicações do aborto provocado e as condições de sua prática. A pesquisa foi desenvolvida em $1990 \mathrm{em}$ uma universidade brasileira. Os dados foram obtidos através de um questionário distribuido a todas as funcionárias e alunas da graduação.

Foram respondidos $42 \%$ dos questionários das alunas e $27 \%$ dos das funcionárias; 82 alunas e 264 funcionárias tinham feito pelo menos um aborto provocado; 15 e 50 , respectivamente, tiveram problemas de saúde (complicações) após o último aborto. As mulheres que tiveram o aborto realizado por médico, em clínica ou hospital, e praticado por métodos mais modernos apresentaram menos complicações. As mulheres mais jovens não foram significativamente diferentes das outras com relação à frequiência das complicações. Entretanto, esse grupo esteve representado principalmente por alunas com maior nivel de educação e, geralmente, mais recursos econômicos.

Palavras-Chave: Aborto Provocado; Complicações; Aborto Ilegal

\section{REFERÊNCIAS BIBLIOGRÁFICAS}

BARROSO, C. L. M. \& CUNHA, M. C., 1980. $O$ que é aborto? São Paulo: Cortez.

COX, D. R., 1970. The analysis of binary data. London: Methuen \& Co. Ltd.

HARDY, E.; REBELLO, I.; RODRIGUES, T. \& MORAES, T. M., 1991. Aborto provocado: diferenças entre pensamento e ação. Revista Brasileira de Ginecologia e Obstetricia, 2: 111. 
LADIPO, A., 1988. Tratamento do aborto incompleto: prevençăo e controle das complicaçôes imediatas. Trabalho apresentado no Christopher Tietze International Symposium, Rio de Janeiro, 29 - 30 outubro. (Mimeo.)

SCHOR, N., 1991. Morbidade e mortalidade por aborto. Trabalho apresentado no Seminário Nacional: A realidade do aborto no Brasil. Embú, Săo Paulo, 25 - 27 outubro. (Mimeo.)
TIETZE, C. \& HENSHAW, S. K. (eds), 1986. Induced abortion - World Review, 1986. New York The Alan Guttmacher Institut.

VERARDO, M. T., 1987. Aborto - um direito ou um crime? Såo Paulo: Editora Moderna. 